\title{
Tingkat Self Esteem Siswa Kelas XII pada Pembelajaran Matematika Daring
}

\author{
Herri Sulaiman $^{1 *}$, Felicia Shabrina ${ }^{2}$, Sri Sumarni ${ }^{3}$ \\ 1,2,3Pendidikan Matematika, Universitas Swadaya Gunung Jati \\ Jalan Pemuda Raya No.32, Sunyaragi, Kota Cirebon, Jawa Barat, Indonesia \\ 1*herrimsc@gmail.com; 2Feliciashabrina26@gmail.com; \\ ${ }^{3}$ srisumarni226@gmail.com
}

Artikel diterima: 07-11-2021, direvisi: 17-05-2021, diterbitkan: 31-05-2021

\begin{abstract}
Abstrak
Self-esteem merupakan salah satu faktor yang mempengaruhi kesuksesan siswa dalam pencapaian akademik. Self-esteem yang rendah ditunjukkan oleh sifat siswa yang cenderung malas dan kurang fokus dalam belajar. Tujuan penelitian untuk mengetahui tingkat self-esteem siswa kelas XII SMA Majalengka tahun ajaran 2019/2020. Metode penelitian ini kuantitatif melalui pengambilan data terkait self-esteem siswa. Adapun sampelnya ialah 72 siswa dari kelas XII IPS. Hasil penelitian saat pembelajaran daring, dapat diketahui bahwa rata-rata skor terendah untuk self-esteem siswa terdapat pada indikator keseriusan dan fokus ketika belajar matematika. Artinya mayoritas siswa kurang fokus ketika belajar matematika saat pembelajaran daring, dan motivasi yang muncul dari dalam dirinya sangat kurang sehingga keseriusan dalam belajar matematika juga kurang. Sedangkan untuk skor tertinggi berada di indikator kepuasan diri yang didapat siswa ketika mereka berhasil mempelajari matematika. Tentu saja ini sebanding dengan usaha yang dilakukan siswa agar dapat berhasil dalam belajar matematika yaitu dengan belajar dan berlatih matematika dengan tekun.

Kata Kunci: Angket, Kemampuan Self-Esteem, Metode Kuantitatif.
\end{abstract}

\section{Level of Self Esteem of Class XII Students in Online Mathematics Learning}

\begin{abstract}
Self-esteem is one of the factors that influence student success in academic achievement. Low self-esteem is indicated by the nature of students who tend to be lazy and less focused on learning. The research objective was to determine the level of self-esteem of class XII SMA Majalengka students in the 2019/2020 school year. This research method is quantitative through data collection related to student self-esteem. The sample is 72 students from class XII IPS. The results of research when learning online, it can be seen that the lowest average score for students' self-esteem is on the indicators of seriousness and focus when learning mathematics. This means that the majority of students are less focused when learning mathematics during online learning, and the motivation that comes from within them is very lacking so that they are not serious about learning mathematics. Meanwhile, the highest score is in the indicator of self-satisfaction obtained by students when they are successful in learning mathematics. Of course, this is comparable to the efforts made by students to be successful in learning mathematics, namely by studying and practicing mathematics diligently.

Keywords: Questionnaire, Self-Esteem Ability, Quantitative Method.
\end{abstract}




\section{Pendahuluan}

Bagi individu, pendidikan merupakan hal yang penting sebagai proses dalam menjalani roda kehidupan (Patterson \& Cavanaugh, 2020). Pendidikan tidak lepas dari karir seseorang dalam meniti kesuksesan dan asa sebagai wujud eksistensi dan pencapaian diri. Melalui pendidikan, individu dapat dipandang dengan baik oleh diri sendiri maupun lingkungan masyarakat sekitar. Semakin tinggi pendidikan seseorang maka ekpektasi orang-orang sekitar semakin tinggi pula (Yale, 2019). Namun, pendidikan tidak hanya didapat dari sekolah/ univ/ college saja melainkan dari pengalaman baik itu diri sendiri ataupun lingkungan sekitarnya (Parameswara, 2021). Melalui pengalaman tersebut dapat dijadikan pelajaran berharga bagi seseorang agar melangkah lebih baik dan maju lagi pada masa depan.

Berbicara tentang mutu pendidikan tentunya berkaca kepada negara Indonesia sebagai negara yang berkembang dan memiliki penduduk yang cukup banyak jumlahnya dan salah satu terbanyak di dunia. Tentunya sebagai negara berkembang dan memiliki jumlah penduduk yang banyak, problematika dalam hal pendidikan sudah menjadi hal yang lumrah dihadapi oleh negara ini (Septian, 2017; Rohayani, 2020). Kebijakankebijakan strategis yang didesain oleh pemerintah khususnya Kemendikbud RI dalam rangka meningkatkan mutu pendidikan di Indonesia selalu mengalami pasang surut (As' ad, Natsir, \& Munir, 2018). Sepertinya ada pukulan telak bagi pemerintah terutama pihak Kemendikbud $\mathrm{RI}$ yang telah mengetahui hasil survei yang dirilis oleh PISA yang menempatkan Indonesia berada di peringkat 72 dari 77 negara (Fauzi \& Suryadi, 2020; Tasman, 2020) dalam hal kemampuan membaca, matematika dan sains. Ini menjadi PR besar bagi bangsa Indonesia yang dikomandoi oleh Kemendikbud RI agar menaikkan peringkat Indonesia dalam sisi mutu pendidikan.

Berbagai cara ditempuh oleh pemerintah dalam menaikkan standar mutu pendidikan di Indonesia. Salah satunya ialah guru-guru perlu dilatih dan ditingkatkan kompetensinya agar kemampuan dalam mengajar siswa semakin terasah dengan baik. Saat ini banyak sekali program-program yang dicanangkan oleh pemerintah dalam rangka meningkatkan kompetensi guru salah satunya melalui PPG (Program Profesi Guru). Melalui program ini diharapkan kompetensi guru dapat meningkat dan tentunya dapat tunjangan profesi juga. Pemerintah berharap dengan adanya tunjangan profesi maka guru-guru di Indonesia semakin semangat dalam mengajar dan lebih kreatif dan inovatif (Aliyudin, Junaedi, \& Prasetyo, 2021) mengimplementasikan media pembelajaran yang lebih mutakhir. Sehingga kebutuhan belajar siswa yang diharapkan dari guru kelasnya dipenuhi dengan maksimal. Ketika guru memiliki kemampuan mengajar yang baik dan kreatif, maka tujuan pembelajaranpun akan tercapai. Bloom berpendapat bahwa tujuan pembelajaran terdiri atas 3 domain, yakni kognitif, afektif, dan psikomotorik (Firmasari \& Herri, 2019). Guru yang kreatif dapat menjangkau semua ranah yang diungkapkan oleh Bloom. Ranah 
kemampuan afektif harus dipantau dan diperhatikan secara khusus oleh guru di kelas. Terutama untuk jenjang pendidikan menengah atas. Karena kenakalan remaja sangat rentan di jenjang ini. Tidak dapat dipungkiri bahwa banyak sekali terjadi tawuran antar pelajar yang didominasi oleh pelajar SMA atau sederajat. Jangankan untuk fokus atau rajin belajar, di dalam pikiran siswa tersebut sudah tertanam rasa brutal, kebencian dan emosi yang diluapkan ke arah tawuran. Kasus inilah yang menjadi PR besar untuk guru kelas, sekolah dan pemerintah tentunya agar fokus menangani kasus seperti ini. Menurut (Pamungkas \& Yani, 2017) berpendapat bahwa perilaku remaja yang kurang fokus dalam belajar dan cenderung memiliki sifat malas merupakan salah satu gejala dari self-esteem yang rendah. Perlu diketahui bahwa self-esteem merupakan salah satu faktor yang dapat mempengaruhi kesuksesan siswa dalam pencapaian akademik (Asakereh \& Yousofi, 2018; Li, dkk., 2018). Apabila self-esteem siswa bagus, maka nilai akademiknya juga baik dan reputasi siswa tersebut juga baik. Tentunya hal ini juga berpengaruh terhadap rasa percaya diri untuk tampil di tengah-tengah lingkungan masyarakat. Demikian sebaliknya.

Pembelajaran daring telah dilakukan semenjak tahun 2020. Karena adanya Pandemi Covid 19, maka pemerintah mewajibkan untuk melakukan pembelajaran secara daring/ online. Banyak sekali platform yang ditawarkan untuk mendukung pembelajaran online ini (Afriansyah, dkk., 2020). Mulai dari tatap muka secara virtual via google meeting room atau zoom meeting room, atau via google classroom dan whatsaap group (Pramuditya, Herri, \& Wahyudin, 2019). Dalam hal ini kemahiran menggunakan IT mutlak diperlukan oleh guru-guru di berbagai jenjang pendidikan (Raharjo \& Herri, 2017). Di era pandemi sekarang ini guru dituntut untuk melakukan pembelajaran yang kreatif dan inovatif, terutama penggunaan media pembelajaran berbasis digital. Kemudian sekolah seharusnya memiliki Learning Management System (LMS) tersendiri untuk menunjang kegiatan pembelajaran via daring/ online ini. Pembelajaran online membutuhkan perangkat pendukung seperti kapasitas internet/wifi, laptop dan smartphone. Perangkat inilah yang digunakan oleh guru dan siswa dalam melaksanakan kegiatan belajar mengajar secara online. Siswa dapat mengakses link dari rumahnya sehingga pembelajaran dapat dilaksanakan (Pramuditya \& Herri, 2019). Dengan demikian, melalui pembelajaran online ini pemerintah berharap kasus terinfeksi Covid 19 dapat diminimalisir. Melalui pembelajaran daring ini guru dapat berinteraksi dengan siswa dan dapat membuat assessment atau penilaian terkait evaluasi hasil belajar siswa melalui uji tes. Guru dapat mengetahui kemampuan dari masing-masing siswa, termasuk aktivitas belajar siswa saat proses pembelajaran berlangsung. Disinilah peran self-esteem dapat terlihat. Melalui dugaan awal yaitu data hasil evaluasi belajar, guru dapat mengetahui dan mendiagnosis apakah siswa yang memiliki nilai tes rendah ada kemungkinan mengalami gejala selfesteem yang rendah pula. 
Perlu diketahui self-esteem merupakan pengakuan eksistensi diri baik posistif maupun negatif yang dipengaruhi oleh keadaan di lingkungan sekitarnya (Meškauskienè, 2017). Eksistensi diri berupa penerimaan, penghargaan ataupun perlakuan secara positif ataupun negatif dari orang-orang terdekatnya (Firmasari, Herri, Wahyu \& Muchamad, 2019). Menurut Yunita dkk. (2019), self-esteem terdiri dari dua yaitu global self-esteem dan spesifik self-esteem. Global self-esteem lebih cenderung pada rasa berharga dan kepercayaan diri sendiri dari berbagai aspek. Sedangkan spesifik self-esteem lebih cenderung pada rasa berharga dan kepercayaan diri sendiri hanya pada salah satu bidang atau aktivitas saja. Bagi siswa, self-esteem harus terus dipupuk dan dikembangkan oleh siswa itu sendiri, tentunya dengan dukungan positif dari keluarga, teman ataupun orang-orang di lingkungan sekitarnya. Apabila tidak demikian, maka akan terjadi ketidakpercayaan diri, menimbulkan sifat malas, motivasi untuk maju sangat rendah yang ujungnya akan bermuara kepada rasa rendah diri yang menganggap diri sendiri tidak memiliki potensi atau bakat apapun. Selain itu dalam hal akademik akan mempengaruhi motivasi belajar yang rendah, hasrat untuk memahami dan berhasil dalam belajar sangat rendah dan menghilangkan daya fokus saat belajar di sekolah. Hal ini dikarenakan siswa tidak mau untuk bekerja keras dan menganggap diri sendiri rendah yang tidak memiliki kemampuan apa-apa (Yunita, Anggita \& Herri, 2019). Tentunya ini sangatlah berbahaya, mengingat siswa-siswi ialah generasi muda milenial yang mana sebagai generasi penerus bangsa yang akan menggantikan kepemimpinan untuk masa depan.

Di sisi lain, siswa yang memiliki selfesteem tinggi sangat percaya diri, dan memiliki kepuasan tersendiri akan pencapaian kemampuan dirinya (Tridinanti, 2018). Dia merasa dirinya sangat berharga, dan selalu berpikir positif terhadap masalah yang diberikan. Dia merasa yakin dapat menyelesaikan atau memecahkan tiap permasalahan yang diberikan. Dari dalam dirinya timbul motivasi untuk bisa, dan selalu menganggap masalah sebagai tantangan yang dapat dia selesaikan dengan baik. Apabila dia memiliki kekurangan akan capaian tertentu, dia tidak segan-segan untuk memperbaiki dan berlatih agar apa yang menjadi kekurangannya dapat ditutupi dengan baik. Selain itu, saat pembelajaran berlangsung, dia aktif untuk memberikan ide awal ketika diskusi dengan guru ataupun teman sekelompoknya. Aktif untuk bertanya kepada guru akan topik yang sedang didiskusikan, dan tentunya dia tidak canggung saat memberikan penjelasan kepada teman-temannya ketika ada yang bertanya. Biasanya, siswa yang memiliki self-esteem tinggi sangat disukai oleh lingkungan sekitarnya dan dijadikan sebagai panutan dan andalan oleh orang-orang di sekitarnya.

Sementara, siswa yang memiliki selfesteem rendah cukup sulit mengekspresikan dirinya sendiri. Ketika berbicara, seseorang yang dijadikan lawan bicara cukup kebingungan akan apa yang disampaikan oleh siswa ini. Biasanya penjelasan yang disampaikannya tidak begitu jelas, bahkan dirinya sendiri tidak 
paham akan apa yang dia sampaikan. Hal ini tentunya diakibatkan karena rasa kurang percaya diri yang timbul dari dirinya sendiri. Selain itu, rasa malu yang berlebihan, cemas, sikap yang kurang tenang, nerveous, ikut mendukung gejala gejala yang ada pada siswa ini. Karena pikiran negatif yang timbul dari siswa ini, menimbulkan rendahnya hasrat untuk belajar, motivasi dan daya fokus yang rendah dalam belajar, juga dapat timbul karenanya, Maharani dkk. (2019). Timbulnya gejala self-esteem yang rendah juga dipengaruhi oleh keluarga, teman dan orang-orang yang berada di lingkungan sekitarnya. Untuk mengatasi hal ini, peran orang tua dan guru sangat mempengaruhi dalam mengubah pola pikir siswa yang memiliki gejala self-esteem yang rendah ini. Bimbingan khusus mutlak diperlukan agar mengembalikan pola pikir positif untuk siswa ini. Di sekolah, siswa ini perlu dapat bimbingan secara khusus dalam tiap mata pelajarannya, agar kemampuannya dapat berkembang. Tentunya, ini tidak mudah dilakukan oleh guru, mengingat kesibukan dalam menyusun administrasi pembelajaran. Namun, menurut penulis inilah yang menjadi tantangan bagi guru yang sebenarnya wajib dilakukan untuk membimbing atau membina bagi siswasiswi yang memiliki gejala self-esteem yang rendah ini. Selain itu, orang tua di rumah juga sebaiknya fokus untuk memperhatikan perkembangan kemampuan akademik anak-anaknya agar dapat terpantau dan selalu mengevaluasi akan hasil belajar anak tiap semesternya. Dengan demikian, dengan upaya tersebut setidaknya dapat meningkatkan nilai self-esteem siswa menjadi lebih tinggi dari sebelumnya Irmawan dkk. (2019).

Dalam penelitian ini ditemukan bahwa selama pembelajaran daring, fokus dan keseriusan siswa dalam pembelajaran kurang, sedangkan kepuasan diri siswa ketika berhasil mempelajari matematika tinggi. Penelitian ini bisa menjadi acuan bagaimana guru mempersiapkan pembelajaran supaya bisa tetap menjaga fokus dan keseriusan siswa dalam belajar matematika secara daring, seperti halnya ketika pembelajaran tatap muka sebelum terjadinya masa pandemi covid ini.

Hasil penelitian yang dilakukan oleh Verdianingsih (2018) menyatakan bahwa guru memiliki peranan penting dalam membentuk self-esteem siswa dalam pembelajaran matematika, self-esteem berperan penting dalam membentuk karakter siswa bahwa dirinya mampu dalam menyelesaikan permasalahan matematika, dan hal ini sangat jelas sangat mempengaruhi prestasi belajar siswa dalam pembelajaran matematika.

Hasil penelitian Wardani dan Yunarti (2015) menyatakan bahwa pembelajaran berbasis masalah memberikan pengaruh positif terhadap self-esteem juga prestasi siswa. Sedangkan penelitian Fadillah (2012) menyatakan bahwa self-esteem siswa yang mendapatkan pembelajaran open ended lebih baik daripada siswa yang mendapatkan pembelajaran biasa. Hal ini menunjukkan bahwa self-esteem siswa selain dipengaruhi oleh guru juga dipengaruhi oleh pembelajaran yang disajikan.

Dari penjelasan sebelumnya dapat dilihat perbedaan penelitian ini dengan 
penelitian sebelumnya yaitu penelitian ini dilakukan untuk melihat tingkat selfesteem siswa selama pembelajaran daring yang dilakukan pada siswa kelas XII IPS. Penelitian ini dipandang sangat penting untuk dilakukan karena sebagai salah satu masukan bagi guru untuk bisa selalu mengupayakan penyajian pembelajaran daring dengan tetap menjaga fokus dan keseriusan siswa selama mengikuti pembelajaran daring sehingga siswa juga merasakan kepuasan diri ketika berhasil belajar matematika.

\section{Metode}

Penelitian ini menggunakan metode kuantitatif, dengan mengambil data terkait self-esteem melalui penyebaran angket kepada siswa kelas XII IPS di SMAN Majalengka. Perhitungan skor diperoleh dengan menjumlahkan seluruh skor dari tiap item pertanyaan hingga mendapatkan skor total. Angket yang disebar berdasarkan indikator dari self-esteem dari teori Sumarmo (2015; Handayani \& Sulisworo, 2021). Lebih lanjut, skor yang didapat dikelompokkan menjadi tiga kategori yaitu tinggi, sedang dan rendah, melalui konversi skor mentah menjadi skor T dengan langkah-langkah sebagai berikut:

1. Menghitung skor total masing-masing responden.

2. Mengkonversi skor responden menjadi skor baku.

Sampel dalam penelitian ini berjumlah 72 siswa kelas XII IPS yang dipilih secara random. Teknik pengumpulan data yaitu dengan menyebarkan angket ke 72 responden yang mana angket ini berisi 10 pertanyaan. Selain itu data didapat pula dari hasil perhitungan skor, lalu dikelompokkan mejadi tiga kategori selfesteem. Berdasarkan tujuan dari penelitian yang dilakukan, secara lebih rinci berikut disajikan alur atau tahapan penelitian yang dilakukan pada Gambar 1 berikut.

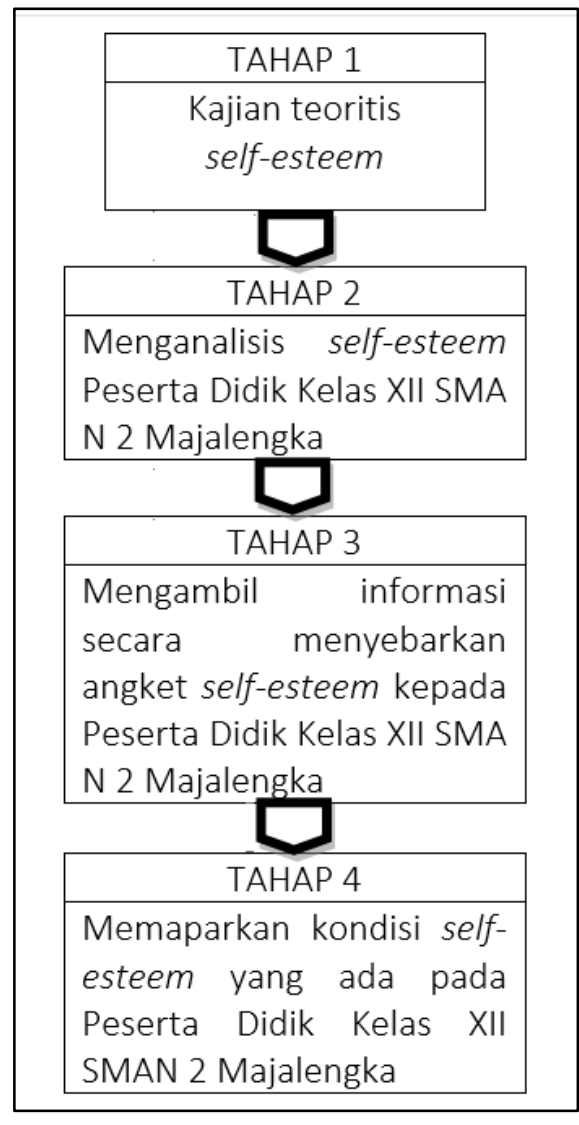

Gambar 1. Tahapan penelitian.

\section{Hasil dan Pembahasan}

Hasil dari penelitian ini menunjukkan tingkat self-esteem siswa kelas XII IPS secara keseluruhan berada pada kategori sedang dengan persentase $65,5 \%$. Artinya siswa memiliki rasa percaya diri yang cukup baik ketika belajar matematika yang diwujudkan dengan penghargaan terhadap diri sendiri dan penghargaan dari temanteman di sekolahnya. Selain itu rasa motivasi dan hasrat untuk belajar matematika cukup baik walaupun skor yang didapat dari angket tidak terlau tinggi. Skor tertinggi ada di indikator kepuasan diri 
yang didapat siswa ketika mereka berhasil mempelajari matematika. Tentu saja ini sebanding dengan usaha yang dilakukan siswa agar dapat berhasil dalam belajar matematika yaitu dengan belajar dan berlatih matematika dengan tekun. Sedangkan skor terendah terdapat pada indikator keseriusan dan fokus ketika belajar matematika. Hal ini menandakan bahwa mayoritas siswa kurang fokus ketika belajar matematika saat pembelajaran daring, dan motivasi yang muncul dari dalam dirinya sangat kurang sehingga keseriusan dalam belajar matematika juga kurang.

Self-esteem bersifat dinamis, artinya indikator yang ada di dalamnya dapat berubah seiring berjalannya waktu. Contohnya ialah siswa yang dulunya hasrat belajar kurang, bisa jadi dapat berubah dengan lebih rajin dan tekun. Sundawan, dkk. (2019) menjelaskan self-esteem adalah evaluasi terhadap dirinya sendiri yang menganggap diri sangat berharga dan sadar akan pengembangan diri agar menjadi pribadi yang lebih baik dalam berbagai aspek. Secara lebih rinci, data tentang tingkat self-esteem siswa kelas XII IPS dapat dilihat dalam tabel berikut.

Tabel 1.

Tingkat Self-Esteem Siswa SMA di Majalengka pada Pembelajaran Online

\begin{tabular}{lcc}
\hline Kategori & Frekuensi & Presentase \\
\hline Tinggi & 0 & $0 \%$ \\
\hline Sedang & 72 & $65,5 \%$ \\
\hline Lemah & 0 & 0
\end{tabular}

Dari Tabel 1 dapat diketahui bahwa tingkat self-esteem siswa SMA Kelas XII IPS berada di level sedang dengan skor 65,5\%. Hal ini berarti siswa-siswi kelas XII memiliki tingkat self-esteem bertaraf sedang. Namun dapat memiliki potensi untuk menigkatkan self-esteem hingga level tinggi. Peran lingkungan sekitar siswa cukup mendominasi agar dapat mempengaruhi kenaikan self-esteem ini. Dukungan positif dari keluarga terutama orang tua dalam memperhatikan anaknya dalam belajar matematika, termasuk memberikan fasilitas yang memadai dalam proses belajar di rumah dapat membuat siswa menjadi nyaman untuk belajar. Sedangkan dukungan di sekolah terutama guru ikut mendominasi pengaruh kenaikan self-esteem. Guru yang positif, kreatif dan inovatif ketika melakukan proses kegiatan KBM secara daring dapat membuat motivasi siswa dapat meningkat. Misalkan guru memberikan materi atau topik yang ada di dalam pelajaran Matematika seperti topik turunan fungsi dengan mengupload video pembelajaran yang dibuat oleh guru itu sendiri melalui aplikasi Camtasia. Dari sini siswa dapat menonton video dan paham akan penjelasan yang disampaikan guru dan bertanya kepada guru ketika ada projek yang guru berikan untuk diselesaikan oleh siswa. Kegiatan diskusi dapat berjalan ketika siswa saling tukar menukar ide atau pendapat antar temantemannya dalam satu kelompok dengan bimbingan atau arahan dari guru. Contoh seperti inilah yang diharapkan mampu untuk meningkatkan hasrat, kemauan, dan motivasi siswa untuk belajar matematika. Dengan demikian, di era pandemi covid 19 saat ini, guru harus memiliki kemampuan lain selain mengajar yaitu menggunakan aplikasi-aplikasi sebagai pendukung pembelajaran berbasis digital. Peran 
teman-teman di sekolah maupun di lingkungan rumah siswa juga menjadi pengaruh yang cukup besar dalam meningkatkan self-esteem siswa. Apabila siswa berada di dalam lingkaran pertemanan yang positif dengan temantemannya di sekolah, maka daya fokus dan kepercayaan diri siswa juga dapat dipertahankan. Hal inilah yang dapat mengembangkan sifat pemimpin, toleransi antar teman, saling mendukung, bersaing secara sportif dan selalu berpikiran positif. Dengan lingkaran pertemanan yang positif ini, siswa lebih semangat dalam belajar matematika dan memiliki pemikiran yang kreatif, inovatif dan mandiri ketika berdiskusi dengan teman-temannya (Khodaria, Anggita \& Herri, 2019).

Posisi self-esteem yang berada di level sedang, sangat rentan berpotensi turun ke level rendah. Hal ini disebabkan apabila proses pembelajaran online yang dilakukan tidak dapat berjalan dengan optimal dan jauh dari capaian pembelajaran yang diharapkan. Berbagai macam faktor dapat menentukan turunnya tingkat self-esteem tersebut diantaranya ialah peran orang tua dalam memperhatikan aktivitas belajar online untuk anak-anaknya. Dalam hal ini, perhatian orang tua mutlak diperlukan untuk mengawasi dan memberikan dorongan dan motivasi kepada siswa agar lebih tekun dalam belajar. Apabila tidak dilakukan demikian, maka tentunya anak merasa bebas dan berprilaku sesuai dengan keinginannya saja, mengingat pembelajaran online yang jauh dari pengawasan dan arahan guru di sekolah, karena siswa belajar di rumah masingmasing. Selain itu, guru dituntut untuk mengajar dengan kreatif dan inovatif mengaplikasikan platform media pembelajaran berbasis digital yang mutakhir, agar pembelajaran yang diberkan tidak membosankan bagi siswa. Dengan demikian, hal inilah yang menjadi tantangan bagi guru di sekolah agar dapat menguasai IT termasuk aplikasi-aplikasi mutakhir yang mendukung proses KBM secara online dengan baik. Namun, masih banyak guru-guru di sekolah yang hanya menggunakan whatsaap group, google classroom dan yang lainnya dalam melaksanakan kegiatan KBM secara online. Selama ini, video pembelajaran hanya diambil dari youtube saja bukan dibuat oleh guru itu sendiri, kemudian diupload di whatsaap group ataupun google classroom. Setelah itu siswa disuruh melihat dan menanggapi. Evaluasi yang dilakukan guru berupa tugas dan tes yang mana siswa-siswi di sekolah saling copymencopy jawaban dari temannya. Dampak yang terjadi ialah guru kebingungan dalam memberikan penilaian karena jawaban siswa secara keseluruhan sama satu dengan yang lainnya. Guru sulit membedakan, mana siswa yang memiliki kemampuan akademik yang sangat baik, baik, sedang ataupun kurang. Kendala yang dialami guru ini disebabkan karena guru itu sendiri yang tidak dapat menguasai IT berupa aplikasi yang lebih mutakhir dalam mendukung kegiatan KBM secara online ini. Kendala lain bisa berasal dari siswa itu sendiri yang mana, keterbatasan perangkat pembelajaran seperti laptop, smartphone, kuota internet dan lain sebagainya dapat membuat siswa untuk malas belajar. Keterbatasan alat pendukung belajar yang dialami siswa dapat menurunkan semangat 
dan motivasinya untuk belajar matematika lebih mendalam.

Dengan demikian, dari kendala-kendala yang dialami saat pembelajaran online ini, dapat memberikan pengaruh negatif kepada siswa-siswi sehingga self-esteem dapat turun ke posisi rendah. Hal ini berpotensi kepada siswa mengalami gejala seperti: harga diri rendah atau memiliki karakteristik mudah putus asa (Marpaung \& Wati, 2020), merasa tidak menarik, kurang ada kemauan dalam menghadapi dan mengatasi kekurangan dalam dirinya (Jabri, Elihami, \& Ibrahim, 2020), enggan mengeskpresikan diri dalam kelompok sehingga merasa terisolir dan sulit bergaul (Settles, Buchanan, \& Dotson, 2019), takut menegur dan marah pada orang yang berbuat salah (Grusec, Danyliuk, Kil, \& O'Neill, 2017), dan kurang berhasil dalam menjalin hubungan interpersonal (Raharjo, Herri \& Ika, 2017).

Self-esteem yang berada di posisi sedang memiliki karakteristik yang berada diantara kedua tingkatan yaitu tinggi dan rendah. Penilaian tentang kemampuan dirinya serta keberartian dirinya bersifat positif. Siswa memandang dirinya lebih baik dari kebanyakan orang pada umumnya tetapi juga tidak terlalu percaya diri. Siswa sudah dikenal cukup baik oleh lingkungan sosialnya, serta menyenangi hal-hal yang tidak penuh dengan tuntutan seperti tugas, projek, maupun diskusi yang diberikan oleh guru. Selain itu cenderung tidak yakin akan ide ataupun gagasan yang dia berikan, cenderung takut menghadapi respon dari orang lain, tidak mampu membina komunikasi yang baik dan cenderung merasa hidupnya tidak bahagia.
Hasil penelitian menyimpulkan bahwa self-esteem siswa dipengaruhi oleh guru juga pembelajaran yang disajikan. Hal ini sejalan dengan hasil penelitian sebelumnya yang menyebutkan bahwa peran guru sangatlah penting dalam pembentukan self-esteem siswa (Verdianingsih, 2018; Laksiwati \& Retnowati, 2019; Wildaniati, 2020).

\section{Penutup}

Berdasarkan penjelasan di atas bahwa self-esteem siswa kelas XII IPS termasuk dalam kategori sedang. Hal ini perlu ditingkatkan oleh dukungan positif dari orang-orang yang ada di lingkungan sekitar siswa. Apabila siswa berada di lingkungan yang negatif maka self-esteem yang tadinya berada di kategori sedang akan berpotensi turun ke level rendah. Pembelajaran online saat ini sangat rentan membuat kategori self-esteem dapat turun apabila orangorang di lingkungan sekitar siswa tidak mendukung secara positif.

\section{Daftar Pustaka}

Afriansyah, E. A., Sofyan, D., Puspitasasri, N., Lurytawati, I. P., Sundayana, R., Maryati, I., Noordyana, M. A., \& Basuki, B. (2020). Edmodo E-learning Media Training for Learning Optimization. Journal Pekemas, 3(2), 33-39.

Aliyudin, M., Junaedi, D., \& Prasetyo, A. (2021). Pengaruh Honor terhadap Peningkatan Kinerja Guru di YPI Al Amanah Cibinong-Bogor. As-Syar'i: Jurnal Bimbingan \& Konseling Keluarga, 3(1), 1-16. 
As' ad, A., Natsir, M., \& Munir, A. A. (2018). Dinamika Penyelenggaraan Madin Takmiliyah di Kabupaten Jepara. Elementary: Jurnal IImiah Pendidikan Dasar, 4(2), 107-124.

Asakereh, A., \& Yousofi, N. (2018). Reflective thinking, self-efficacy, selfesteem and academic achievement of Iranian EFL students in higher education: Is there a relationship?. International Journal of Educational Psychology, 7(1), 68-89.

Fadillah, S. (2012). Meningkatkan Self-

Esteem Siswa SMP dalam Matematika melalui Pembelajaran dengan Pendekatan Open Ended. Jurnal Pendidikan MIPA, 13(1), 34-41.

Fauzi, I., \& Suryadi, D. (2020). Didactical Design Research untuk Mengembangkan Kompetensi Pedagogik Guru di Sekolah Dasar. INVENTA: Jurnal Pendidikan Guru Sekolah Dasar, 4(1), 58-68.

Firmasari, S., \& Herri, S. (2019). Kemampuan Pembuktian Matematis Mahasiswa Menggunakan Induksi Matematika. Journal of Medives: Journal of Mathematics Education IKIP Veteran Semarang, 3(1), 1-9.

Firmasari, S., Herri, S., Wahyu, H., \& Muchamad, SN. (2019). Rigorous mathematical thinking based on gender in the real analysis course. Journal of Physics: Conference Series. 1157(4), 042106.

Grusec, J. E., Danyliuk, T., Kil, H., \& O'Neill, D. (2017). Perspectives on parent discipline and child outcomes. International Journal of Behavioral Development, 41(4), 465471.
Handayani, I. M., \& Sulisworo, D. (2021). Pengembangan Media Pembelajaran Matematika Berbantuan Geogebra Pada Materi Transformasi Geometri. Jurnal Equation: Teori dan Penelitian Pendidikan Matematika, 4(1), 47-59.

Irmawan, W., Mohammad, D. S., \& Herri, S. (2019). Peningkatan Keterampilan Self Advocacy (SA) Mahasiswa melalui Teknik Structure Learning Approach (SLA) Pada Topik Fungsi Real. MAJU: Jurnal IImiah Pendidikan Matematika, 6(1), 23-31.

Jabri, U., Elihami, E., \& Ibrahim, I. (2020). The effects of approach instruction on student's reading performance. Jurnal Edukasi Nonformal, 1(1), 72-80.

Khodaria, S., Anggita M., \& Herri, S. (2019). The Analysis of Item Problems in High School Mathematics Textbook in Indonesia (2016 Revision Edition) Reviewed From The Cognitive Aspect of TIMSS. Indonesian Journal of Learning and Instruction, 2(1), 13-21.

Laksmiwati, P. A., \& Retnowati, E. (2019). Pengembangan perangkat pembelajaran geometri berbasis kecerdasan majemuk siswa SMP kelas VIII. Pythagoras: Jurnal Pendidikan Matematika, 14(1), 1-11.

Li, J., Han, X., Wang, W., Sun, G., \& Cheng, Z. (2018). How social support influences university students' academic achievement and emotional exhaustion: The mediating role of selfesteem. Learning and Individual Differences, 61, 120-126.

Maharani, A., Herri S., Neneng A., \& Cita, DR. (2019). Analyzing the student's cognitive abilities through the thinking 
levels of geometry van hiele reviewed from gender perspective. Journal of Physics: Conference Series. 1188(1), 012066.

Marpaung, I. M. N., \& Wati, C. L. S. (2020). Hubungan Antara Harga Diri, Efikasi Diri Akademik, dan Penyesuaian Diri Terhadap Lingkungan Sekolah Para Siswa Kelas VII di SMP St. Kristoforus 1. Psiko Edukasi, 18(1), 18-31.

Meškauskienè, A. (2017). The impact of teaching environment on adolescent self-esteem formation. European Journal of Social Science Education and Research, 4(3), 112-120.

Pamungkas, A. S., \& Yani, S. (2017). Peranan Pengetahuan Awal dan Self Esteem Matematis Terhadap Kemampuan Berpikir Logis Mahasiswa. Jurnal Matematika Kreatif-Inovatif, 8(1), 61-68.

Parameswara, M. C. (2021). Optimalisasi Pendidikan Karakter pada Siswa Sekolah Dasar. Jurnal Pendidikan Tambusai, 5(1), 1621-1630.

Patterson, K. B., \& Cavanaugh, T. (2020). Assistive technology in the transition education process. In Handbook of Adolescent Transition Education for Youth with Disabilities (pp. 236-248). Routledge.

Pramuditya, S. A., \& Herri, S. (2019). Analisis Kebutuhan Game Edukasi Mahasiswa dalam Menyelesaikan Materi Prasyarat Persamaan Diferensial. Journal Euclid, 6(1), 74-83. Pramuditya, S. A., Herri, S., \& Wahyudin. (2019). Development of instructional media game education on integral and differential calculus. IOP Conference Series Publishing. 1280(4), 042049.

Raharjo, J. F., \& Herri, S. (2017). Mengembangkan Kemampuan Pemahaman Konsep Matematika Diskrit Dan Pembentukan Karakter Konstruktivis Mahasiswa Melalui Pengembangan Bahan Ajar Berbantuan Aplikasi Education Edmodo Bermodelkan Progresif Pace (Project, Activity, Cooperative and Exercise). Teorema: Teori Riset dan Matematika, 2(1), 47-62.

Raharjo, J. F., Herri, S., \& Ika, W. (2017). The Study of Mathematical Modeling Development Based on Realistic Approach as Prototype Learning to Improve Students Mathematical Problem Solving Ability in Differential Equation Subject. Repository FKIP Unswagati.

Rohayani, F. (2020). Menjawab Problematika yang Dihadapi Anak Usia Dini di Masa Pandemi Covid19. Qawwam, 14(1), 29-50.

Septian, A. (2017). Penerapan Geogebra untuk Meningkatkan Kemampuan Pemecahan Masalah Matematis Mahasiswa Program Studi Pendidikan Matematika Universitas Suryakancana. Prisma, 6(2), 180-191.

Settles, I. H., Buchanan, N. T., \& Dotson, K. (2019). Scrutinized but not recognized:(In) visibility and hypervisibility experiences of faculty of color. Journal of Vocational Behavior, 113, 62-74.

Sundawan, M. D., Wawan, I., \& Herri, S. (2019). Kemampuan Berpikir Relasional Abstrak Calon Guru 
Matematika dalam Menyelesaikan Soal-Soal Non-Rutin pada Topik Geometri Non-Euclid. Mosharafa: Jurnal Pendidikan Matematika, 8(2), 319-330.

Tasman, F. (2020). Designing PISA Like Problems for West Sumatra Mathematics and Science Junior High School Teachers. Pelita Eksakta, 3(1), 75-81.

Tridinanti, G. (2018). The correlation between speaking anxiety, selfconfidence, and speaking achievement of Undergraduate EFL students of private university in

Palembang. International Journal of Education and Literacy Studies, 6(4), 35-39.

Verdianingsih, E. (2018). Self-Esteem dalam Pembelajaran Matematika. Edusco, 3(2), 7-15.

Wardani, E. P., \& Yunarti, T. (2015). Meningkatkan Self-Esteem dan Prestasi Belajar Matematika Siswa melalui Pembelajaran Berbasis Masalah. Seminar Nasional Matematika dan Pendidikan Matematika UNY, 511-516.

Wildaniati, Y. (2020). Efektifitas Metode Team Assisted Individualization Dalam Pembelajaran Matematika di SD Dilihat Dari Self-Esteem Siswa. Jurnal Dewantara, 9(01), 53-68.

Yale, A. T. (2019). The personal tutorstudent relationship: student expectations and experiences of personal tutoring in higher education. Journal of Further and Higher Education, 43(4), 533-544.

Yunita, D. R., Anggita, M., \& Herri, S. (2019). Identifying of Rigorous
Mathematical Thinking on Olympic Students in Solving Non-routine Problems on Geometry Topics. 3rd Asian Education Symposium (AES 2018) Atlantis Press. 495-499.

\section{Riwayat Hidup Penulis}

\section{Herri Sulaiman.}

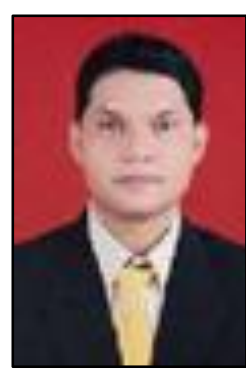

Lahir di Maguwoharjo (Sleman), 3 Juni 1987. Staf pengajar di Universitas Swadaya Gunung Jati (UGJ) Prodi Pendidikan Matematika. Studi S1 Matematika Terapan Universitas Gajah Mada, Yogyakarta, lulus tahun 2009; S2 Matematika Terapan Universitas Gajah Mada, Yogyakarta, lulus tahun 2012. Pernah menjadi admin IT Program Profesi Guru (PPG) daljab di LPTK FKIP UGJ Tahun 20182020.

\section{Felicia Shabrina.}

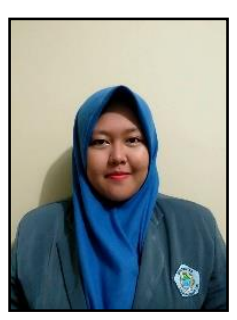

Lahir di Kota Majalengka, (26Agustus 1999). Mahasiswa di Universitas Swadaya Gunung Jati (UGJ) Prodi Pendidikan Matematika Studi S1. Infromasi publikasi terbaik yang pernah menjadi Pemakalah seminar Pendidikan Matematika.

\section{Sri Sumarni.}

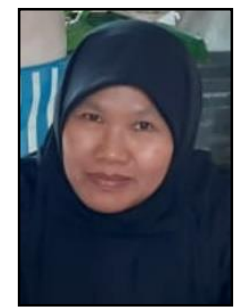

Lahir di Cimahi Bandung 22 maret 1968 Studi D3 Pendidikan Matematika di UPI Bandung lulus th 1990, S1 Pendidikan Matematika di UT. Menjadi Staf Pengajar Matematika di SMAN 2 Majalengka (1997-2020). 